\title{
AÇÕES COLETIVAS: A MATERIALIZAÇÃO DA RESPONSABILIDADE SOCIAL UNIVERSITÁRIA NO CURSO DE PEDAGOGIA DO ISECENSA
}

\author{
Angela Barros Fonseca Berto ${ }^{1 *}$, Karla Osiris Freire Leal ${ }^{1}$, Amanda dos Santos Hora ${ }^{2}$ \& \\ Raquel Vilaça da Mata ${ }^{2}$
}

\section{RESUMO}

BERTO, A. B. F.; LEAL, K. O. F.; HORA, A. S.; MATA, R. V. Ações coletivas: a materialização da responsabilidade social universitaria no curso de Pedagogia do ISECENSA. Perspectivas Online: Humanas \& Sociais Aplicadas, v.9, n.26, p.62-81, 2019.

A possibilidade de aplicação dos princípios da responsabilidade social universitária às ações coletivas do curso de Pedagogia do ISECENSA implica na reflexão crítica, na discussão interna, na busca pelo alinhamento de concepções e posicionamento institucional visando a produzir resposta que atenda às demandas da sociedade, agindo, pois, em conformidade com a missão, a identidade e cultura da instituição de ensino. Para Carrizo (2006) é um tema que merece uma discussão profunda pela comunidade acadêmico-científica nas áreas de ensino, pesquisa e extensão. Neste contexto, o presente estudo tem como objetivos conhecer os impactos das ações coletivas realizadas pelo curso de Pedagogia do ISECENSA na perspectiva de seus receptores/participantes; compreender $\mathrm{o}$ conceito de responsabilidade social, redefinindo o novo papel da universidade; exercitar a função interativa com a sociedade, influenciando, de maneira proativa e com sentido de equidade, a comunidade que está no entorno. Buscouse verificar se as ações coletivas vêm obtendo visibilidade e cumprindo com os objetivos estabelecidos. O presente estudo delineia-se como uma pesquisa qualitativa do tipo descritiva, caracterizada pela análise e coleta de dados arrecadados tal como ocorrem espontaneamente. A coleta de dados foi feita por meio da observação participante, utlizando como instrumentos entrevistas semi-estruturadas e coleta de depoimentos com os receptores participantes das ações que são foco deste estudo. Após a coleta de dados, fizemos a transcrição e a análise das falas dos entrevistados, para então levantarmos as categorias de análise, para cada projeto. Os resultados supõem a necessidade de dar continuidade às ações coletivas desenvolvidas pelo curso de Pedagogia visto que as mesmas são reconhecidas pela comunidade, como incentivo à apropriação de cultura, à aprendizagem, à interação, à autonomia, à inovação e à responsabilidade social. Tais ações tornam-se práticas acadêmicas por excelência, que possibilitam não somente o aperfeiçoamento das competências técnicas, mas também o desenvolvimento de valores e princípios direcionados ao desenvolvimento humano.

Palavras-chave: Responsabilidade Social; Pedagogia; Ações Coletivas. 


\section{ABSTRACT}

The possibility of applying the principles of university social responsibility to the collective actions of the ISECENSA Pedagogy course implies in the critical reflection, the internal discussion, the search for the alignment of conceptions and institutional positioning in order to produce a response that meets the demands of society, in accordance with the mission, the identity and culture of the educational institution. For Carrizo (2006) it is a topic that deserves a deep discussion by the academic-scientific community in the areas of teaching, research and extension. In this context, the present study aims to know the impacts of the collective actions carried out by the ISECENSA Pedagogy course from the perspective of its recipients/ participants; understanding the concept of social responsibility, redefining the new role of the university; to exercise the interactive function with the society, influencing, in a proactive way and with a sense of fairness, to the community that is in the surroundings. It was sought to verify if collective actions have been gaining visibility and complying with established objectives. The present study is delineated as a qualitative research of the descriptive type, characterized by the analysis and collection of data collected as they occur spontaneously. Data collection was done through participant observation, using as instruments semi-structured interviews and collection of statements with the participants participating in the actions that are the focus of this study. After the data collection, we did the transcription and analysis of the interviewees' speeches, and then we collected the analysis categories for each project. The results suppose the need to continue the collective actions developed by the Pedagogy course since they are recognized by the community as an incentive to the appropriation of culture, to learning, to interaction, to autonomy, to innovation and to social responsibility. These actions become academic practices par excellence, which enable not only the improvement of technical skills, but also the development of values and principles directed to human development.

Keywords: Social Responsibility; Pedagogy; Collective Actions.

\footnotetext{
1 Institutos Superiores de Ensino do CENSA - ISECENSA - Laboratório de Formação de Professor - LAFORP - Rua Salvador Correa, 139, Centro, Campos dos Goytacazes, RJ, CEP: 28035-310, Brasil.

${ }^{2}$ Alunas do Programa Voluntário de Iniciação Científica-PROVIC- Institutos Superiores de Ensino do CENSA - ISECENSA - Rua Salvador Correa, 139, Centro, Campos dos Goytacazes, RJ, CEP: 28035-310, Brasil.

(*) e-mail: berto.angela@gmail.com

Data de recebimento: 20/09/2019. Aceito para publicação:13/11/2019.
}

Persp. Online: hum \& sociais aplicada., Campos dos Goytacazes, 26 (9) 62-81- 2019 seer.perspectivasonline.com.br 


\section{INTRODUÇÃ̃}

Recentemente, cresceu em importância a Responsabilidade Social Universitária - RSU nos diferentes âmbitos acadêmicos, dada sua contribuição para a formação de estudantes e comunidades socialmente responsáveis.

Várias organizações já começaram a aceitar que somos interdependentes, que existe a necessidade do outro, bem como a importância de consolidar o compromisso entre as pessoas, a fim de alcançar um desenvolvimento humano para todos e para cada um de nós.

Nesse novo cenário, um movimento que começa a surgir é o de avaliar as atividades de responsabilidade social que estão sendo executadas. Dirigentes, clientes, investidores e a sociedade também passam a se preocupar em avaliar o grau com que a responsabilidade social está sendo exercida pelas instituições. A empresa/instituição torna transparente a sua atuação e assume um efetivo compromisso com a ética e a sustentabilidade social e ambiental do planeta, sustentando o pressuposto de que a responsabilidade social agrega valor à marca, fortalece os vínculos comerciais e sociais (ASHLEY, 2002).

Ao exercer a responsabilidade social, a instituição de ensino superior coloca seus conhecimentos, talentos e recursos a serviço da comunidade. Está ajudando a construir um mundo melhor para todos. Ações coletivas que promovem o envolvimento $\mathrm{e}$ comprometimento dos alunos, são boas não apenas para a instituição, mas também para a sociedade como um todo.

Segundo François Vallaeys (2006, p. 39):

[...] a Responsabilidade Social Universitária exige, a partir de uma visão holística, a articulação das diversas partes da instituição, em um projeto de promoção social de princípios éticos e de desenvolvimento social eqüitativo e sustentável, com vistas à produção e transmissão de saberes responsáveis e à formação de profissionais cidadãos igualmente responsáveis.

As ações coletivas realizadas no curso de Pedagogia dos Institutos Superiores de Ensino do CENSA - ISECENSA tornam-se um meio de propagar e aplicar a Responsabilidade Social Universitária na medida em que estabelecem uma parceria instituição-comunidade em que a instituição se torna corresponsável pelo desenvolvimento cultural e social da comunidade.

Ao atuar com responsabilidade social a instituição também estimula a prática do voluntariado diluída em valores como altruísmo e solidariedade, além do potencial transformador que tal prática representa para o crescimento interior do próprio indivíduo. Para tanto recorremos à categoria de pesquisa da educação não-formal (GOHN, 2006) na qual nos ocupamos em definir a categoria, delimitar seu campo e apontar lacunas e necessidades para a ampliação de seu entendimento e campo de estudo.

Neste trabalho, ao investigarmos sobre a questão do sentido e significado da educação produzida nas ações coletivas protagonizadas pelas redes associativas da sociedade civil, retomamos a categoria da educação não-formal, não mais como construção teórico-abstrata, mas como ferramenta operacional de análise. Mas a passagem de categoria abstrata para categoria operacional transitou pela mediação de novas reflexões e elaborações, pois sentimos

Persp. Online: hum \& sociais aplicada., Campos dos Goytacazes, 26 (9) 62-81- 2019 seer.perspectivasonline.com.br 
a necessidade de aprofundar o estudo sobre as lacunas antes apontadas, principalmente as de ordem metodológica.

Neste sentido, originou-se a primeira parte deste texto, tendo sido elaborado para ser um aprofundamento da categoria "educação não-formal" objetivando sua operacionalização já que a consideramos central no trabalho de um pedagogo social.

\subsection{O novo papel da universidade}

Discutir se a finalidade principal da educação superior deve ou não ser a formação de profissionais com forte formação ética e cidadã não mais se sustenta, já que se trata de uma demanda social mundial e, além de tudo, faz parte das exigências quanto às diretrizes curriculares da maior parte dos cursos. $\mathrm{O}$ que se discute, com propriedade, é de que forma cidadania e ética podem ser estimuladas no ensino superior. E mais: como organizar os conteúdos e as atividades curriculares para dar vida a um profissional socialmente mais responsável?

Há um consenso em torno da ideia de que a universidade não só pode como deve cumprir uma missão que ultrapassa os limites da sua finalidade tradicional de produção, reprodução, divulgação e conservação do conhecimento. Requer-se, hoje, da instituição universitária não só a formação de recursos humanos de alto nível de qualificação, mas também que proporcione uma educação que prepare para o pleno exercício da cidadania; requer-se não só que contribua para o avanço do conhecimento científico e tecnológico, mas também que a sua atividade de pesquisa esteja voltada para a resolução de problemas e de demandas da comunidade na qual está inserida e alinhada a um modelo de desenvolvimento que privilegia, além do crescimento da economia, a promoção da qualidade de vida.

Segundo Cortella (2015, p. 53), significa debater cidadania de forma a atender tais demandas. Para o autor, tais questões "abrangem toda e qualquer ação em sociedade, portanto, toda e qualquer família, em instituições religiosas e sociais, no mundo das relações de trabalho". Acrescenta que, dessa forma, pretende-se dar à cidadania um ar de ideia nobre, honesta, de valor positivo à medida em que, na Educação, "nós mudamos com processos processos de vida, processos humanos, processos de conhecimento. Os processos são sempre mudança $[. .]$.$" .$

Assim sendo, privada ou pública, somente uma universidade de qualidade, com autonomia e compromisso social com a mudança, será capaz de promover a produção do conhecimento, a inovação tecnológica, associar o universal às peculiaridades regionais e formar, além do profissional, o cidadão. Estas instituições serão capazes de contribuir decisivamente para um projeto de desenvolvimento sustentado que garanta não apenas a melhoria dos indicadores econômicos, mas, sobretudo, daqueles que expressam avanços sociais (MACEDO, 2006).

A promoção do ensino socialmente responsável abarcaria a formação de indivíduos qualificados para a inclusão no mercado profissional e igualmente a formação de pessoas críticas, moralmente competentes, capazes de tomada de decisões frente a questões éticas.

A formação humanística, tão importante para a conquista da equidade e da inclusão social, deixaria de ser um conteúdo relegado a certas disciplinas, usualmente no primeiro ano dos diversos cursos, e passaria a ser conteúdo transversal de toda matriz curricular. Tudo isso

Persp. Online: hum \& sociais aplicada., Campos dos Goytacazes, 26 (9) 62-81- 2019 seer.perspectivasonline.com.br 
envolve a capacitação para ir além do reconhecimento de problemas ambientais no sentido amplo da palavra. Envolve a formação de indivíduos capazes de, se não solucionar esses problemas, influenciá-los na resolução.

Urge, neste contexto, a necessidade de que a formação de profissionais pedagogos seja também a partir de um conhecimento empírico, no sentido de proporcionar esta experiência com a sociedade observando assim a contribuição da Pedagogia Social na vida das pessoas. Um conhecimento que procura incorporar e transformar a realidade ao mesmo tempo em que se vão modificando as relações do sujeito com o entorno.

Concorda-se com Carbonell (2002), quando ele afirma que um dos dez componentes do novo conhecimento inovador é aquele que olha o entorno para interpretá-lo e tratar de transformá-lo. O autor argumenta sobre o aprender a olhar o meio e descobri-lo com todas as suas grandezas e misérias, seus conflitos, seus consensos, suas contradições e possibilidades de mudança.

As Ações Coletivas desenvolvidas pelo curso de Pedagogia e seus temas transversais abarcam toda a relação entre "escola e entorno" dando a este último, a oportunidade e o direito ao conhecimento, à educação.

Segundo Pena-Vega e Morin (2003 apud CARRIZO, 2006, p. 76):

Os desafios específicos a serem destacados pela universidade são, de um lado, seu papel na produção e difusão dos saberes e, de outro, seu espaço em termos de cidadania, seu papel social, cultural e político e as responsabilidades geradas por este espaço.

Pena-Vega e Morin (2003) afirma ainda que, o papel da universidade fica cada dia mais estratégico e decisivo. Tanto do ponto de vista social, político, cultural e econômico, quanto da perspectiva da complexidade do mundo real, o conhecimento é a chave em termos de transformação e em termos de cidadania e responsabilidade social. A universidade deve repensar-se tendo como norte de suas reflexões a condição humana.

Para Morin, Ciurana e Motta (2003), nossa formação escolar, universitária e profissional transforma a todos em cegos políticos, assim como nos impede de assumir, de uma vez por todas, nossa necessária condição de cidadãos da Terra. A urgência vital de "educar para a era planetária" é decorrência disso, e requer três reformas inteiramente interdependentes: uma reforma do modo de conhecimento, uma reforma do pensamento e uma reforma do ensino. Nesta concepção, nossa instituição promove o envolvimento, o compromisso do curso de Pedagogia na transformação, entendendo que a realidade muda e que, como cidadãos do mundo, somos corresponsáveis na construção da consciência nesta sociedade-mundo.

Neste aspecto, Freire (1980) ressalta que a educação problematizadora está fundamentada sobre a criatividade e estimula uma ação e uma reflexão verdadeiras sobre a realidade e acrescenta que a educação, é deste modo, continuamente refeita pela práxis.

Para Jiménez de La Jara et al. (2006), as universidades têm por missão criar conhecimento e formar cientistas e outros profissionais voltados para o atendimento das necessidades de desenvolvimento do país. Os temas referentes à pobreza, à desintegração social, ao desenvolvimento do capital social, à proteção dos recursos naturais - em outras

Persp. Online: hum \& sociais aplicada., Campos dos Goytacazes, 26 (9) 62-81- 2019 seer.perspectivasonline.com.br 
palavras, o desenvolvimento sustentável - deveriam estar no centro das preocupações de todos.

Trilhar os caminhos da prestação de serviços, mediante a definição e a implementação de projetos e programas estruturados e com garantia de continuidade, tem sido um excelente instrumento para as instituições de ensino superior participarem efetivamente do desenvolvimento social e oferecerem às comunidades locais forte contribuição para a melhoria da qualidade de vida e o aprimoramento da produção de bens e serviços. Com isso, em contrapartida, as instituições de ensino superior ganham identidade e passam a ser reconhecidas pela sua capacidade de inserção regional, pela sua sensibilidade para identificar e atender as demandas regionais (MACEDO, 2006, p. 11.).

As atividades desenvolvidas e os atendimentos prestados, escritórios de prática jurídica e clínicas-escola, dentre outros, cumprem o duplo papel de integração da formação dispensada aos estudantes, viabilizando o treinamento de competências e o exercício da cidadania e de prestação de serviços à comunidade.

O papel da universidade cidadã, neste contexto, é contribuir para criar condições que promovam a cidadania, através da socialização da informação, da discussão, da transparência, gerando uma nova mentalidade, uma nova cultura frente à comunidade no seu entorno.

Para Gadotti e Padilha (2004, p. 132), “[...] o grande desafio da escola numa cidade educativa é traduzir princípios em experiências práticas inovadoras, em projetos para a capacitação cidadã da população, para que ela possa tomar em suas mãos o destino da sua cidade".

Cortella (2015, p. 56) ressalta que:

solidariedade, sinceridade, fraternidade, respeito, honestidade, são princípios a serem experimentados em situações que a escola pode criar, seja no debate de situações-limite (trazendo casos de rupturas ou de consolidação ética), seja por meio de atividades colaborativas e comunitárias.

É urgente uma reflexão da instituição acadêmica sobre si mesma, no contexto de seu entorno social e de uma análise de sua parcela de responsabilidade quanto aos problemas crônicos da sociedade. Como ressalta Freire (1980), os homens são capazes de agir conscientemente sobre a "realidade objetivada". É precisamente isto, a "práxis humana", a unidade indissolúvel entre minha ação e minha reflexão sobre o mundo.

\subsection{As diversas áreas de atuação do Pedagogo}

O novo cenário da Educação vem permeado de inúmeras possibilidades não só laborativas como de formação contínua para seus profissionais. O pedagogo, neste conjunto, tem novas alternativas fora do campo escolar, os chamados "espaços não-escolares" Empresas, hospitais, ONGs, associações, eventos, dentre outros, formam hoje o novo campo de atuação deste profissional, que transpõe os muros da escola, para prestar seu serviço. Essa atual realidade vem rompendo paradigmas e ideias de que o pedagogo está apto para exercer suas funções somente na sala de aula. Vê-se que, onde houver uma prática educativa, poderá existir uma ação pedagógica.

Os cursos de Pedagogia hoje têm como objetivo a formação de profissionais capazes de exercer a docência na Educação Infantil, nos anos iniciais do ensino Fundamental, nas

Persp. Online: hum \& sociais aplicada., Campos dos Goytacazes, 26 (9) 62-81- 2019 seer.perspectivasonline.com.br 
disciplinas pedagógicas para a formação de professores, assim como para a participação no planejamento, gestão e avaliação de estabelecimentos de ensino, de sistemas educativos escolares, bem como organização e desenvolvimento de programas não-escolares.

Outras demandas, no entanto, vêm surgindo no trabalho do pedagogo, tais como: hospitais, empresas, movimentos sociais.

Segundo Wolf (2007), um desses campos não-escolares da atuação do pedagogo é a pedagogia hospitalar que funciona como uma parceria entre o hospital, a universidade representada pelos estagiários e a instituição escolar de onde o paciente é oriundo. $\mathrm{O}$ pedagogo através da escolarização hospitalar garante a continuidade dos estudos das crianças hospitalizadas, promovendo a adaptação, a motivação, e a ocupação sadia do tempo ocioso através de atividades de leitura, garantindo o direito a educação. Sua atuação pode se dar na ala de recreação do hospital, ou com as crianças que necessitam de estimulação essencial, com classe hospitalar de escolarização para continuidade dos estudos e no atendimento ambulatorial.

Para Matos e Mugiatti (2006, p. 67),

este novo papel com que se depara a Pedagogia Hospitalar compreende os procedimentos necessários à educação de crianças e adolescentes hospitalizados, de modo a desenvolver uma singular atenção pedagógica aos escolares que se encontram em atendimento hospitalar e ao próprio hospital na concretização dos seus objetivos.

Acrescentam ainda, que

este enfoque educativo e de aprendizagem deu origem à ação pedagógica em hospitais pediátricos, nascendo da convicção de que a criança e o adolescente hospitalizados, em idade escolar, que não devem interromper, na medida do possível, seu processo de aprendizagem, seu processo curricular educativo (MATOS; MUGIATTI, 2006, p. 67).

Por sua vez, a atuação do pedagogo voltada à educação ambiental e sustentabilidade, traz a possibilidade de autorreflexão e o capacita para compreender a sua corresponsabilidade para a construção de um mundo sustentável. Grandisoli e Ribeiro (2015, p. 19), ressaltam que "um dos componentes chave na direção de mudanças amplas que queremos ver no mundo é a Educação no seu sentido mais amplo (Educação Formal, Não-formal e Informal), uma vez que todos os espaços e relações são, de alguma forma, educadores".

De acordo com Grandisoli e Ribeiro (2015), a Pedagogia Sustentável na prática, muda hábitos ao explorar formas de economia e reaproveitamento de água e de diversos materiais, a refletir sobre recursos renováveis e não renováveis, gera conscientização e contribui para a preservação do planeta,

O trabalho focado na sustentabilidade contempla diferentes níveis de atuação dos profissionais da educação em conjunto com todo o restante da comunidade escolar e do entorno. Repensar o espaço de forma coletiva e democrática envolve, obrigatoriamente, uma mudança na forma de ver a educação, a escola e seus relacionamentos, e isso envolve também uma nova forma de aprendizagem e, por que não, um novo currículo mais livre e cocriado. (GRANDISOLI; RIBEIRO, 2015).

Persp. Online: hum \& sociais aplicada., Campos dos Goytacazes, 26 (9) 62-81- 2019 seer.perspectivasonline.com.br 
Atendendo às demandas do mundo moderno, o pedagogo ganha espaço também nas empresas. Lopes (2009, p. 30), nos diz que a pedagogia empresarial se apresenta como uma ponte entre o desenvolvimento das pessoas e as estratégias organizacionais. Isto porque, a pedagogia é a ciência que estuda de forma sistematizada o ato educativo, isto é, a prática educativa concreta que se realiza na sociedade.

Ribeiro (2010, p. 10), destaca que:

o pedagogo empresarial torna-se corresponsável pela promoção de um clima organizacional saudável, sendo articulador entre as peculiaridades organizacionais, expressas em termos de perfis de desempenho considerados ideais para cada cargo/função, e os desejos e as aspirações dos grupos de pessoas que a compõem. Espera-se dele uma visão de mundo mais ampla de modo que se possam propor projetos que interfiram positivamente no comportamento das pessoas, assumindo-as, de fato, como os elementos essenciais da organização.

O pedagogo também atua buscando estratégias, a partir de temas transversais educativos em contextos diversos, com o objetivo de promover melhora na qualidade de vida das pessoas envolvidas. A Pedagogia Social permite ao graduando, não somente conhecer e vivenciar as realidades, mas também transformá-las.

Concorda-se com Oliveira (1993, p. 102), quando diz que "a educação é uma área interdisciplinar e aplicada, que se alimenta de formulações teóricas originárias de várias disciplinas e que se constrói no plano da prática". Neste aspecto, podemos dizer que as ações coletivas possibilitam a reflexão-ação, o entrelaçamento entre a teoria e a prática bem como a ampliação das áreas de atuação do pedagogo.

\subsection{As ações coletivas do curso de Pedagogia: a prática da cidadania e da responsabilidade social}

As instituições de ensino superior não podem se distanciar desse movimento de Responsabilidade Social, tal como nos afirma Vallaeys (2006), que se fortalece na mesma proporção em que se fortalece a sociedade civil brasileira, organizando-se na busca da construção de um mundo mais próspero, mais humano, menos violento, com desenvolvimento econômico equânime e oportunidades iguais para todos haja vista que o Estado não mais consegue dar conta de tantas demandas oriundas da sociedade.

Organizar e participar de ações coletivas é uma forma de envolvimento dos alunos em busca de alternativas para problemas reais da comunidade em que vive.

O curso de Pedagogia dos Institutos Superiores de Ensino do CENSA promove o exercício desta cidadania na medida em que oportuniza experiências voluntárias de serviço à comunidade, quer em asilos, shoppings, praças, comunidades assistidas, hospitais.

Nesse contexto, existem ganhos de aprendizado para ambas as partes, pois ali se estabelece uma relação de complementaridade, pressuposto básico à boa convivência e realização da coletividade humana. Ações com tais pressupostos formam não só cidadãos, comprometidos socialmente nas respectivas ações de ensino, pesquisa e extensão. Formam, sobretudo, seres humanos fraternos que se valorizam reciprocamente, ainda que haja a constante eminência da diversidade. Ou seja, formam seres "abertos ao outro", capazes de se sensibilizarem pelos demais considerando contextos diversos.

Persp. Online: hum \& sociais aplicada., Campos dos Goytacazes, 26 (9) 62-81- 2019 seer.perspectivasonline.com.br 
A RSU exige, numa visão holística, articular as diversas partes da instituição em um projeto de promoção social com princípios éticos e de desenvolvimento social, eqüitativo e sustentável, para a produção e transmissão de saberes responsáveis e pela formação de cidadãos igualmente responsáveis (VALLAEYS, 2006, p. 15).

Segundo Gohn (2006), a educação não-formal poderá desenvolver nos indivíduos a consciência e organização de como agir em grupos coletivos; a construção e reconstrução de concepções de mundo e sobre o mundo; a contribuição para um sentimento de identidade com uma dada comunidade; a formação de um indivíduo para a vida e suas adversidades (e não apenas capacitá-lo para entrar no mercado de trabalho); o resgate do sentimento de valorização de si próprio. Enfim, um maior conhecimento de sua própria prática, de leitura e interpretação do que os cerca.

A partir das Ações Coletivas, realizadas no curso de pedagogia do ISECENSA, a instituição atua com responsabilidade social em ambientes não-escolares, estimula também a prática do voluntariado diluída em valores como altruísmo e solidariedade, além do potencial transformador que tal prática representa para o crescimento interior do próprio indivíduo.

É importante ressaltar que uma ação coletiva é composta por práticas racionais (com referência a fins e a valores). As Ações Coletivas implementadas, originaram-se nos temas transversais trabalhados no curso, atendendo às diferentes modalidades de práticas nas instituições escolares e não-escolares e que foram e são articuladas pela equipe de professores, alunos e pela coordenação do curso.

As ações possibilitam a atuação dos graduandos em múltiplos espaços, reforçando a prática pedagógica, a responsabilidade social, que possibilita aos discentes, adentrar o campo de estágio desenvolvendo ações embasadas em conhecimento prático, teórico e científico (MANCUR, 2001).

Dentro dessa perspectiva, tais práticas se tornam primordiais para que docentes e discentes comecem a construir uma relação de co-responsabilização pelas ações que serão implementadas, uma vez que ambos entram em contato direto com as necessidades cotidianas, inseridas em um contexto social.

\section{METODOLOGIA}

Uma pesquisa é, de alguma forma, um relato de longa viagem empreendida pelo pesquisador cujo olhar o faz pensar determinada realidade de uma forma diferente a partir de uma experiência e de uma apropriação do conhecimento muito próprias (DUARTE, 2002).

De acordo com Brandão (2000), a "construção do objeto" diz respeito, entre outras coisas, à capacidade de optar pela alternativa metodológica mais adequada à análise daquele objeto. Se nossas conclusões somente são possíveis em razão dos instrumentos que utilizamos e da interpretação dos resultados a que o uso dos instrumentos permite chegar, relatar procedimentos de pesquisa oferece a outros a possibilidade de refazer o caminho e, desse modo, avaliar com mais segurança as afirmações que fazemos.

Este estudo versa, metodologicamente, sob as perspectivas de Minayo (1999), Trivinos (1987), Parreira et al. (2017) e Martins (1996) cujas contribuições permeiam esta etapa da investigação.

Persp. Online: hum \& sociais aplicada., Campos dos Goytacazes, 26 (9) 62-81- 2019 seer.perspectivasonline.com.br 
Nesse sentido, do ponto de vista da abordagem, esta pesquisa é categorizada como qualitativa (MINAYO, 1999) visto que permitirá identificar e analisar dados não mensuráveis, como motivações e expectativas de um determinado grupo, ao pôr em foco as percepções dos dos participantes ações coletivas desenvolvidas pelo curso de Pedagogia. O contato direto e estreito com o objeto de estudo - neste caso, as ações coletivas e os sujeitos - vem a favorecer o conhecimento de influências que os mesmos sofrem do ambiente em que se inserem. No caso, a relação campo de desenvolvimento das ações/participantes, que pode ser essencial e determinante para a compreensão do fenômeno em estudo.

Quanto aos seus objetivos, identifica-se como pesquisa descritiva (TRIVINOS, 1987) pois lidamos com interpretações da realidade social, a partir das ações coletivas vivenciadas pelo curso de Pedagogia dos Institutos Superiores de Ensino (ISECENSA - Campos dos Goytacazes /RJ - Brasil), cenário da pesquisa.

Enquanto coleta de dados, utilizamos a observação participante, mais adequada para apreender, compreender e intervir nos diversos contextos em que se move esta pesquisa, proporcionando uma aproximação ao cotidiano dos indivíduos e das suas representações sociais, da sua dimensão histórica, sociocultural, dos seus processos (PARREIRA et al., 2017). Por outro lado, permite-nos intervir nesse mesmo cotidiano, e nele trabalhar ao nível das representações sociais, e propiciar a emergência de novas necessidades para os indivíduos que ali desenvolvem as suas atividades (MARTINS, 1996).

$\mathrm{Na}$ observação participante o pesquisador se torna parte de tal universo para melhor entender as ações daqueles que ocupam e produzem culturas, apreender seus aspectos simbólicos, que incluem costumes e linguagem. Além disso, pode gerar uma relação de maior intimidade e confiabilidade entre os envolvidos nesse processo. Um maior envolvimento pessoal permitirá que o pesquisador seja capaz de não apenas entender melhor os significados e as ações que o grupo realiza, como também de prover acesso a um mundo mais privado ou "de bastidores" (MINAYO, 1999).

Elaborou-se, ao longo de cada ação coletiva realizada, uma espécie de "diário de campo", com as descrições "qualitativas", de tipo "narrativo", que permitiram obter informações relevantes dos envolvidos nas ações através da análise de suas falas.

Utilizou-se como amostra cinco ações coletivas desenvolvidas no período de maio/ 2018 a abril/2019 no Curso de graduação em Pedagogia do ISECENSA. O critério de seleção destas ações, dentre tantas outras desenvolvidos no curso, deu-se por serem consideradas ações ocorridas dentro do período da pesquisa.

Após a coleta de dados, realizou-se a transcrição e a análise das falas dos entrevistados, considerando os depoimentos e compondo as unidades de significado, o contexto em que foram colocadas as idéias, a consistência interna, a freqüência e a extensão dos comentários, a especificidade das respostas para então levantar-se as categorias de análise. Para tanto, fez-se esta apreciação na dimensão membros da comunidade que participam dos projetos.

\section{RESULTADOS}

\subsection{ANÁLISE DAS FALAS DOS ENTREVISTADOS}

Persp. Online: hum \& sociais aplicada., Campos dos Goytacazes, 26 (9) 62-81- 2019 seer.perspectivasonline.com.br 

pesquisa.

A seguir, faremos um relato sintético acerca de cada uma das ações investigadas nesta

A primeira ação coletiva a que se refere este estudo, surgiu a partir da reflexão do tema da Campanha da Fraternidade 2017: "Fraternidade: biomas brasileiros e defesa da vida", tendo como lema "Cultivar e guardar a criação". Segundo Boff (1999, p. 134), "para cuidar do planeta precisamos todos passar por uma alfabetização ecológica e rever nossos hábitos de consumo. Importa desenvolver a ética do cuidado". Trata-se de rever atitudes, assumindo novos hábitos de consumo responsável evitando desperdícios, e desenvolvendo uma maior preocupação com o coletivo e não apenas com o indivíduo, na participação das decisões do interesse de todos para a construção da paz.

Envolvidos no tema supracitado, organizamos a nossa "Ação Coletiva no Boulevard Shopping", levando um teatro de fantoches, elaborado em aula, com as alunas, a partir da história infantil "Por um mundo mais bacana" de Lucia Reis (2013). O objetivo foi refletir sobre as diversas situações cotidianas que promovem a violência e ressaltar atitudes que proporcionem a paz, os valores, o bom relacionamento e o senso de responsabilidade socioambiental com as próprias ações.

Em duas sessões de apresentação, estiveram presentes em média 60 crianças que participaram ativamente e, depois, realizaram oficinas de pintura, origami e recorte e colagem, relacionados ao tema. Juntando-se a essas 60 crianças, tivemos também a presença de seus pais, familiares e outros adultos que passeavam pelo shopping e que, portanto, paravam para ver as apresentações. Muitos dos quais, coletamos relatos orais, com perguntas simples e rápidas sobre a percepção que tinham do evento e que fizeram parte do nosso "diário de campo".

A segunda ação, ocorreu durante o processo de revitalização do Horto Municipal, com a inauguração da "Biblioteca Verde", pela Prefeitura Municipal de Campos dos Goytacazes. Os alunos do curso de Pedagogia, envolvidos na ação, fizeram doações de livros infantis para serem utilizados na biblioteca, plantaram sementes de flores e mudas de árvores frutíferas ao longo do espaço do horto. O teatro de fantoches da história "Por um mundo mais bacana", foi apresentado para duas escolas particulares, atendendo a um público de, aproximadamente 90 crianças entre 3 a 9 anos. A temática abordou a construção de uma sociedade sustentável, o respeito e cuidado da comunidade para com os seres vivos, a melhoria da qualidade de vida humana, a modificação de atitudes e práticas pessoais para a preservação ambiental, ressaltando o cuidado com o planeta Terra.

Essas duas primeiras ações coletivas aconteceram no mês de junho/2018 por ocasião do Dia Mundial do Meio Ambiente, comemorado em 05 de junho.

A terceira ação investigada por esta pesquisa e realizada pelo curso aconteceu na enfermaria do Hospital Plantadores de Cana, no mês de julho/2018. Os alunos do curso de Pedagogia fizeram a entrega de bonecas terapêticas, confeccionadas na disciplina de Pedagogia Hospitalar.

As bonecas terapêuticas tem o propósito de criar um fator de identificação importante para elevar a auto estima das crianças, contribuindo assim com a humanização e o sucesso do tratamento médico. Assim, se uma criança tem um problema de coração, a boneca vai com um coraçãozinho nela. Após a doação das bonecas, houve um teatro de fantoches para as

Persp. Online: hum \& sociais aplicada., Campos dos Goytacazes, 26 (9) 62-81- 2019 seer.perspectivasonline.com.br 
crianças internadas na Pediatria. Um momento de alegria e descontração para aliviar a dor e o cansaço que abatem as crianças e seus pais neste contexto. Estes últimos também nos fizeram breves relatos que foram anotados em nosso "diário de campo".

A quarta ação ocorreu em maio/2018, em comemoração ao dia das mães. $\mathrm{O}$ curso presta assistência pedagógica a uma comunidade de baixa renda da cidade, conhecida com Comunidade Tamarindo, através do Projeto Universidade Bairro, cujas crianças recebem apoio no reforço escolar pelos acadêmicos do curso de Pedagogia.

A programação para as mães dessas crianças teve início com uma palestra, ministrada por professoras do curso de Enfermagem da instituição sobre os "Cuidados com a saúde da mulher", no intuito de dotá-las de conhecimento sobre um tema tão relevante. Num segundo momento, foi organizado um animado bingo, com prêmios variados que incluíram também duas cestas básicas.

A quinta e última ação investigada por esta pesquisa, intitulada "Leitura no ponto", ocorreu no mês de abril/2019. Um dos mais significativos projetos sócioacadêmicos desenvolvidos pelo curso de Pedagogia, desde 2016, e que tem como objetivo disseminar a leitura através da distribuição gratuita de livros, em pontos de grande concentração de pessoas.

A ação foi realizada no Terminal Rodoviário da Beira Rio e na praça do Santíssimo Salvador, ambos localizados na área central da cidade. Foram distribuídos mais de 350 títulos, dos mais variados gêneros literários, doados pelos alunos da instituição. Crianças, adultos e idosos receberam os livros com entusiasmo e curiosidade, demostrando grande aprovação na iniciativa que também foi registrada em nosso "diário de campo".

Segundo Minayo (1999), a entrevista é o procedimento mais usual no trabalho de campo. Através dela, o pesquisador procura obter informes contidos na fala dos atores sociais. A entrevista constitui um importante componente da realização de uma pesquisa qualitativa.

Dessa forma, optou-se pela realização de entrevistas semi-estruturadas com os indivíduos envolvidos na realização das ações coletivas investigadas nesta pesquisa. A entrevista, com duração prevista de 10 a 15 minutos, baseou-se em um roteiro previamente elaborado, porém aberto às intervenções de acordo com o feedback dos entrevistados.

Para Triviños (1987, p. 146) a entrevista semi-estruturada tem como característica questionamentos básicos que são apoiados em teorias e hipóteses que se relacionam ao tema da pesquisa. Os questionamentos dariam frutos a novas hipóteses surgidas a partir das respostas dos informantes. O foco principal seria colocado pelo investigador-entrevistador. Complementa o autor, afirmando que a entrevista semi-estruturada "[...] favorece não só a descrição dos fenômenos sociais, mas também sua explicação e a compreensão de sua totalidade [...]" além de manter a presença consciente e atuante do pesquisador no processo de coleta de informações (TRIVIÑOS, 1987, p. 152).

Optou-se por fazer um "diário de campo", com tais entrevistas, utilizando o bloco de notas do celular já que a maioria das ações deu-se em espaços abertos e comunitários, sem grandes acomodações e com grande rotatividade de pessoas da comunidade envolvidas. As repostas dos entrevistados foram ora gravadas ora registradas no "diário de campo" para posterior transcrição e análise da fala dos entrevistados.

Persp. Online: hum \& sociais aplicada., Campos dos Goytacazes, 26 (9) 62-81- 2019 seer.perspectivasonline.com.br 
Para Bauer e Gaskell (2002, p. 287), "uma análise atenta dos dados falados transcritos pode levar a compreensões mais claras sobre os dados coletados". Tal análise fornece um caminho para examinar as categorias dos participantes, descobrindo o que eles tomam como sendo relevante a essas categorias, fornecendo uma explicação explícita para o pesquisador. A análise das falas constitui uma fonte para nossas preocupações teóricas e, ao mesmo tempo, uma abertura ao que nos pode surpreender.

Durante o processo de transcrição, levou-se em conta a fala original dos entrevistados, respeitando-se sua estrutura e suas ideias. Num primeiro momento buscou-se as convergências das falas dos diferentes entrevistados, organizando as mais significativas nas tabelas que seguem para melhor retirarmos das falas as unidades de significados e, posteriormente, selecionou-se as categorias de análise. Tais categorias permitiram uma melhor sistematização dos dados coletados ao longo das entrevistas.

A seguir, tem-se a organização dos relatos/depoimentos dos entrevistados, as unidades de significado e suas respectivas categorias de cada projeto socioacadêmico analisado.

Quadro 1: Teatro de Fantoches "Por um mundo mais bacana” (Shopping Boulevard)

\begin{tabular}{|c|c|c|}
\hline Relatos/ Depoimentos & Unidades de Significado & Categoria \\
\hline $\begin{array}{l}\text { "Minha filha adorou as atividades } \\
\text { que vocês fizeram com ela. Veio me } \\
\text { mostrar uma dobradura que } \\
\text { conseguiu fazer" (mãe de criança) } \\
\text { "Muito legal! O shopping precisa } \\
\text { desse tipo de atividade mais } \\
\text { educativa para as crianças." (pai de } \\
\text { criança) } \\
\text { "Adorei o teatrinho que vocês } \\
\text { apresentaram. Uma mensagem } \\
\text { muito bonita para as crianças." (avó } \\
\text { de criança ) } \\
\text { "Sempre que venho ao shopping, e } \\
\text { tem esse tipo de atividade, eu trago } \\
\text { ela" (tia de criança ) } \\
\text { "Gostei muito das atividades. } \\
\text { Queria que tivesse todo dia" } \\
\text { (criança 1) } \\
\text { "O teatrinho ensinou a gente a } \\
\text { cuidar do mundo, sem violência e } \\
\text { com muita paz." (criança 2) }\end{array}$ & $\begin{array}{l}\text { - Autonomia na execução } \\
\text { das atividades. } \\
\text { - Responsabilidade social } \\
\text { como serviço ao outro } \\
\text { - Atividades interessantes. } \\
\text { - Necessidade de se dar } \\
\text { continuidade ao projeto. } \\
\text { - Cuidado com o outro. }\end{array}$ & $\begin{array}{l}\text { - Aprendizagem } \\
\text { - Continuidade do } \\
\text { projeto }\end{array}$ \\
\hline
\end{tabular}

Persp. Online: hum \& sociais aplicada., Campos dos Goytacazes, 26 (9) 62-81- 2019 seer.perspectivasonline.com.br 
Quadro 2: Educação Ambiental (Horto Municipal)

\begin{tabular}{|c|c|c|}
\hline Relatos/ Depoimentos & Unidades de Significado & Categoria \\
\hline $\begin{array}{l}\text { "Estávamos precisando muito } \\
\text { desses livros que vocês doaram } \\
\text { para nossa Biblioteca Verde" } \\
\text { (coordenador da biblioteca) } \\
\text { "Que bom que vocês trouxeram } \\
\text { uma atividade para fazer com as } \\
\text { crianças. A educação ambiental é } \\
\text { muito importante para ser } \\
\text { trabalhada com elas" (responsável } \\
\text { pela biblioteca) } \\
\text { "Amei o plantio das mudas e o } \\
\text { teatrinho. Muito interesssantes." } \\
\text { (professora) } \\
\text { "Achei interessante uma faculdade } \\
\text { vir aqui fazer este trabalho. Mostra } \\
\text { responsabilidade com } \\
\text { comunidade". (professora) } \\
\text { "A contação de histórias foi ótima. } \\
\text { As crianças participaram bastante } \\
\text { interagindo com os fantoches." } \\
\text { (professora) }\end{array}$ & $\begin{array}{l}\text { - Reconhecimento do } \\
\text { trabalho. } \\
\text { - Importância da Educação } \\
\text { Ambiental }\end{array}$ & $\begin{array}{l}\text { - Responsabilidade } \\
\text { Social. } \\
\text { - Participação e } \\
\text { autonomia }\end{array}$ \\
\hline
\end{tabular}

Quadro 3: Bonecas Terapêuticas (Hospital Plantadores de Cana)

\begin{tabular}{|c|c|c|}
\hline Relatos/ Depoimentos & Unidades de Significado & Categoria \\
\hline $\begin{array}{l}\text { "Minha filha está internada há uma } \\
\text { semana aqui, sem fazer nada. } \\
\text { Agora com essa boneca vai poder } \\
\text { passar o tempo brincando com ela. } \\
\text { Gostei muito." (mãe de criança) } \\
\text { "O teatrinho de fantoches alegrou } \\
\text { as crianças. Tirou a atenção da } \\
\text { doença. Elas se divertiram } \\
\text { bastante" (coordenadora da } \\
\text { enfermaria) } \\
\text { "O trabalho de vocês é um alento } \\
\text { para essas crianças porque algumas } \\
\text { ficam muito tempo aqui na } \\
\text { internação sem ter o que fazer" } \\
\text { (psicopedagoga) } \\
\text { "As bonecas são muito } \\
\text { interessantes e retratam a } \\
\text { enfermidade de cada criança. Não }\end{array}$ & $\begin{array}{l}\text { Reconhecimento do } \\
\text { trabalho } \\
\text { - Aprendizagem constante. }\end{array}$ & $\begin{array}{l}\text { - Reconhecimento } \\
\text { profissional } \\
\text { - Aprendizagem } \\
\text { - Inovação }\end{array}$ \\
\hline
\end{tabular}

Persp. Online: hum \& sociais aplicada., Campos dos Goytacazes, 26 (9) 62-81- 2019 seer.perspectivasonline.com.br 
conhecia essa proposta." (mãe de criança)

Quadro 4: Projeto “Universidade-Bairro" - Dia das Mães (Comunidade Tamarindo)

\begin{tabular}{|c|c|c|}
\hline Relatos/ Depoimentos & Unidades de Significado & Categoria \\
\hline $\begin{array}{l}\text { "Aprendi aqui muitas coisas que eu } \\
\text { não sabia. Foi ótimo " (mãe de } \\
\text { criança) } \\
\text { "A palestra com a psicóloga foi } \\
\text { maravilhosa. Tocou no coração da } \\
\text { gente." (mãe de criança) } \\
\text { "O bingo foi muito divertido. } \\
\text { Adorei! Façam mais!" (mãe de } \\
\text { criança) } \\
\text { "Precisamos desses momentos para } \\
\text { pensarmos melhor sobre como } \\
\text { educar nossos filhos" (mãe de } \\
\text { criança) } \\
\text { "Normalmente não temos tempo } \\
\text { para essas coisas (palestras...) mas } \\
\text { vindo aqui já ajuda porque } \\
\text { passamos a fazer as coisas } \\
\text { corretamente. } \\
\text { - Que bom que vocês tiveram essa } \\
\text { ideia! Essas atividades ajudam } \\
\text { muito as mães da comunidade pois } \\
\text { dão a orientação que muitas vezes } \\
\text { elas não têm" (mãe de criança) }\end{array}$ & $\begin{array}{l}\text { Compromisso com a } \\
\text { comuidade }\end{array}$ & $\begin{array}{l}\text { - Atividades } \\
\text { interessantes }\end{array}$ \\
\hline
\end{tabular}

Quadro 5: "Leitura no Ponto” (Terminal Rodoviário e Praça do Santíssimo Salvador)

\begin{tabular}{|c|c|c|}
\hline Relatos/Depoimentos & Unidades de Significado & Categoria \\
\hline $\begin{array}{l}\text { "Detesto ler. Mas vou pegar um } \\
\text { livro pra te dar atenção. Você vai } \\
\text { ler, né, filho?" (pai de criança) } \\
\text { "Amo livro. Posso pegar mais de } \\
\text { um? Muito legal vocês estarem } \\
\text { fazendo isso" (adolescente - } 17 \\
\text { anos) } \\
\text { "Esse projeto de vocês é } \\
\text { maravilhoso. Muita gente não tem } \\
\text { dinheiro pra comprar livros e assim } \\
\text { fica mais fácil pra ler" (mãe de }\end{array}$ & $\begin{array}{l}\text { Oportunidade de } \\
\text { crescimento. }\end{array}$ & $\begin{array}{l}\text { - Iniciativa } \\
\text { interessante } \\
\text { - Sustentabilidade }\end{array}$ \\
\hline
\end{tabular}

Persp. Online: hum \& sociais aplicada., Campos dos Goytacazes, 26 (9) 62-81- 2019 seer.perspectivasonline.com.br 


\begin{tabular}{|c|c|c|}
\hline $\begin{array}{l}\text { criança) } \\
\text { - A proposta de vocês é muito boa. } \\
\text { Doar livros é dar oportunidades a } \\
\text { pessoas que nunca tiveram na } \\
\text { vida." (adulto) } \\
\text { - Já estive aqui ano passado no } \\
\text { projeto de vocês. Sempre venho. } \\
\text { Muito importante vocês } \\
\text { proporcionarem isso à população de } \\
\text { Campos. }\end{array}$ & $\begin{array}{l}\text { - Responsabilidade Social } \\
\text { com a comunidade. }\end{array}$ & $\begin{array}{l}\text { - Responsabilidade } \\
\text { Social. }\end{array}$ \\
\hline
\end{tabular}

\section{DISCUSSÃO}

Analisando os depoimentos dos entrevistados selecionamos as seguintes categorias: autonomia, reconhecimento profissional, responsabilidade social, inovação e aprendizagem.

Tais categorias apareceram com frequência na análise da fala dos entrevistados. A seguir, ver-se-á cada uma delas confrontando-as com as questões norteadoras da pesquisa, bem como com os autores citados na revisão de literatura.

No que se refere à categoria autonomia foi possível perceber que as ações coletivas promovidas pelo curso estimulam o fazer crítico e competente, tal como aponta Macedo (2006) quando diz que a promoção do ensino socialmente responsável abarcaria a formação de indivíduos qualificados para a inclusão no mercado profissional e igualmente a formação de pessoas críticas, moralmente competentes, capazes de tomada de decisões. A autonomia foi percebida nas ações do curso em vários momentos, quer na pediatria do hospital, quer na ação realizada no horto municipal quer no teatro de fantoches do shopping. (Quadros 1, 2 e 3)

Quanto ao reconhecimento profissional, vê-se que a comunidade externa reconhece os esforços do curso na busca de minimizar o impacto das mazelas sociais que permeiam o entorno em que vivem quer seja por meio da conscientização quer seja por meio de atividades que possibilitem alavancar a participação das pessoas. (Quadros 4 e 5)

Como afirma Jiménez de La Jara et al (2006), as universidades têm por missão criar conhecimento e formar cientistas e outros profissionais voltados para o atendimento das necessidades de desenvolvimento do país. Os temas referentes à pobreza, à desintegração social, ao desenvolvimento do capital social, à proteção dos recursos naturais - em outras palavras, o desenvolvimento sustentável - deveriam estar no centro das preocupações de todos. No caso específico do curso de Pedagogia, as ações coletivas voltaram-se para tais temas tendo como ponto de partida e chegada o ensino e a aprendizagem na medida em que universidade e comunidade dialogam entre si e são, em suas especificidades, espaço de difusão e apropriação de cultura.

No que tange à responsabilidade social, as ações coletivas ocorreram de maneira diversificada buscando aliar o ensino, a pesquisa e a extensão através de suas estratégias e do envolvimento com a comunidade local. Tal como nos inspira Ashley (2002), ao exercer a responsabilidade social, a instituição de ensino superior coloca seus conhecimentos, talentos e

Persp. Online: hum \& sociais aplicada., Campos dos Goytacazes, 26 (9) 62-81- 2019 seer.perspectivasonline.com.br 
recursos a serviço da comunidade. Está ajudando a construir um mundo melhor para todos. Sendo assim, considera-se que as ações coletivas são oportunas não apenas para a instituição, mas também para a sociedade como um todo. (Quadros 1, 2, 4 e 5)

É notória a inovação presente nas atividades desenvolvidas e que faz parte dos relatos de alguns participantes das ações. Há uma admiração pelas propostas apresentadas sendo avaliadas como criativas, interessantes e condizentes com o propósito a que se destinam. (Quadro 3)

Neste aspecto, Freire (1980) ressalta que a educação problematizadora está fundamentada sobre a criatividade e acrescenta que a educação, é deste modo, continuamente refeita pela práxis. As ações coletivas são sempre pensadas e repensadas de modo a buscar atender as demandas da ciência e da sociedade. Dessa forma, há que se pensar em inovação e criatividade como condutoras de uma proposta que se efetive nas práticas socioeducativas.

A categoria aprendizagem também foi bastante citada nas falas dos entrevistados. Articular a educação, em seu sentido mais amplo, com os processos de formação dos indivíduos como cidadãos é uma grande demanda da sociedade atual. (Quadros 1, 3 e 4) Por isso trabalhou-se com um conceito amplo de educação que se materializa nas ações coletivas do curso de Pedagogia.

Corroborando as ideias de Mancur (2001), as ações possibilitaram a atuação dos graduandos, reforçando a prática pedagógica, embasada em conhecimentos empírico, teórico e científico. A formação de cidadãos éticos, ativos, participativos, com responsabilidade diante do outro é condição sine qua non na construção de novas agendas tal como supõe este trabalho. Essas agendas devem contemplar projetos que viabilizem a mudança social, e contemple valores de uma sociedade mais cidadã. A educação não-formal é um espaço valioso na construção e transformação dessa nova realidade social.

\section{CONCLUSÕES}

Esta pesquisa supõe que o papel da universidade vai se tornando cada vez mais estratégico e decisivo visto que ao conhecer de perto a comunidade e seus projetos, pode dar respostas mais concretas aos seus problemas, respeitando peculiaridades regionais, éticas, sociais e culturais. Uma instituição educacional considerada socialmente responsável traz para a academia os dilemas da sociedade e cria um ambiente que fomenta a formação de lideranças, que propõe soluções, intervenções e discussões que contribuem para que a própria sociedade possa superar seus problemas.

O curso de Pedagogia tem reconhecidas suas práticas de responsabilidade social nas ações coletivas que realiza, em cada semestre, numa relação de reciprocidade e enriquecimento mútuo entre seus alunos e a comunidade.

Tais ações tornam-se práticas acadêmicas por excelência, que possibilitam não somente o aperfeiçoamento das competências técnicas, mas também o desenvolvimento de valores e princípios direcionados ao desenvolvimento humano, visto que, ao propor-se atividades a serem realizadas fora da instituição, dá-se a elas o caráter de extensão tão preconizada enquanto condição para a existência de uma instiuição de ensino superior (IES) socialmente responsável.

Persp. Online: hum \& sociais aplicada., Campos dos Goytacazes, 26 (9) 62-81- 2019 seer.perspectivasonline.com.br 
O curso vai ao encontro às demandas da comunidade local, pois entende que deve retornar para esta mesma comunidade os conhecimentos dela oriundos quer em suas pesquisas quer nas experiências que adquire. Não há como negar a relação existente entre a vida acadêmica e a vida da comunidade, bem como suas demandas e aspirações.

Assmann (2000) postula a ideia de que a interdependência é um fato. Para ele, a forma como a vida transcorre diariamente leva a pensar que indivíduos ou grupos sociais são autônomos e independentes. $\mathrm{O}$ que se passa com o outro não atinge a coletividade e nem tem a ver com seu entorno. Muito pelo contrário.

As universidades reúnem o potencial intelectual e instrumental para lidarem de forma estratégica, sistemática, contínua e eficaz na solução dos problemas que afetam a sociedade. Cabe à universidade cuidar para que este conhecimento esteja voltado, efetivamente, para a melhoria da qualidade de vida e a minimização das mazelas sociais.

Há que se considerar também a importância dos vínculos criados a partir do desenvolvimento das ações coletivas. Mães, crianças, jovens, idosos, alunos, professores, enfim, uma infinidade de relações que vão se solidificando a cada nova prática. Tanto social, quanto individualmente falando, são diversos os benefícios que se conseguem alcançar a partir de ações altruístas que emprega-se em nosso dia a dia.

As ações se transformam em exemplos para os que estão ao redor, em constante observação. Neste sentido, acaba-se incentivando os demais a agirem da mesma forma, o que traz consequências altamente benéficas para a sociedade como um todo.

É urgente voltar os olhos para os processos de educação não-formal que se desenvolvem no seio da universidade e que contribuem, de forma efetiva, na formação de um novo modelo civilizatório. Precisa-se de uma nova educação que contribua na formação de um cidadão para atuar, nos dias de hoje, de forma mais crítica, criativa e emancipatória.

Propõe-se, em suma, a articulação da educação formal com a não-formal para dar vida e fomentar mudanças significativas na educação e na sociedade como um todo. Certamente que, nessa perspectiva, o curso de Pedagogia do ISECENSA tem muito a contribuir ao materializar tais mudanças em suas ações coletivas.

\section{REFERÊNCIAS}

ASHLEY, Patríca Almeida. (Coord.). Ética e responsabilidade social nos negócios. São Paulo: Saraiva, 2002.

ASSMANN, Hugo. Competência e sensibilidade solidária: educar para a esperança. Petrópolis: Vozes, 2000.

BAUER, Martim W.; GASKELL, George. Pesquisa qualitativa com texto, imagem e som: um manual prático. Petrópolis: Vozes, 2002.

BOFF, Leonardo. Saber cuidar: ética do humano, compaixão pela terra. Petrópolis: Vozes, 1999.

BRANDÃO, Z. Entre questionários e entrevistas. In: NOGUEIRA, M. A.; ROMANELLI, G.; ZAGO, N. (orgs.). Família \& escola. Rio de Janeiro: Vozes, 2000. p. 171-83.

Persp. Online: hum \& sociais aplicada., Campos dos Goytacazes, 26 (9) 62-81- 2019 seer.perspectivasonline.com.br 
CARBONELL, Jaume. A aventura de inovar: a mudança na escola. Tradução Fátima Murad. Porto Alegre: Artmed Editora, 2002.

CARRIZO, Luís. Conhecimento e Responsabilidade Social: ameaças e desafios para a universidade transdisciplinar. Estudos. Ano 24. N. 36. Junho: 2006.

CORTELLA, Mario Sergio. Educação, convivência e ética: audácia e esperança. São Paulo: Cortez, 2015.

DUARTE, Rosália. Pesquisa qualitativa: reflexões sobre o trabalho de campo. Cadernos de Pesquisa, n. 115, p. 139-154, mar. 2002.

FREIRE, Paulo. Conscientização: teoria e prática da libertação uma introdução ao pensamento de Paulo Freire. Tradução de Kátia de Mello e Silva. 3. ed. São Paulo: Moraes, 1980.

GADOTTI, Moacir; PADILHA, Paulo Roberto; CABEZUDO, Alicia. (orgs). Cidade educadora: princípios e experiências. São Paulo: Cortez, 2004.

GOHN, Maria da Glória. Educação não-formal na pedagogia social. Congresso Internacional de Pedagogia Social [on line]. 2006, ano 1. Disponível em http://www.proceedings.scielo.br/scielo.php? Acesso: 10 mar. 2019.

GRANDISOLI, Edson; RIBEIRO, Livia. Educação e Sustentabilidade: ética e valores para um mundo melhor. Direcional Educador, São Paulo, ano 11, ed. 125, p. 18-20, junho 2015.

JIMENEZ DE LA JARA, Mônica et al. Responsabilidade universitária: uma experiência inovadora na América Latina. Estudos, Brasília, n.36, p.57-73, mar.2006.

LOPES, Izolda (org.). Pedagogia empresarial: formas e contextos de atuação. 3 ed.,Riode de Janeiro: Wak, 2009.

MACEDO, Arthur Roquete de. O papel social da universidade. Ano 24. n. 36. Junho: 2006.

MANCUR, Olson. A lógica da Ação Coletiva. São Paulo: EDUSP, 2001.

MARTINS, João Batista. Observação participante: uma abordagem metodológica para a psicologia escolar. Seminário: Ciências Sociais/Humanas, Londrina, v. 17, n. 3, p. 266-273, set. 1996.

MATOS, Elizete Lúcia Moreira; MUGIATTI, Margarida Maria Teixeira de Freitas. Pedagogia Hospitalar: a humanização integrando educação e saúde. Petrópolis, RJ: Vozes, 2006.

MINAYO, Maria Cecília de Souza. (org.) Pesquisa social: teoria, método e criatividade. Petrópolis: Vozes, 1999.

MORIN, E.; CIURANA, E. R.; MOTTA, R. D. Educar na era planetária: o pensamento complexo como método de aprendizagem pelo erro e incerteza humana. São Paulo: Cortez: Brasília, DF: UNESCO, 2003.

Persp. Online: hum \& sociais aplicada., Campos dos Goytacazes, 26 (9) 62-81- 2019 seer.perspectivasonline.com.br 
OLIVEIRA, Martha Kohl de. Vygotsky: aprendizado e desenvolvimento um processo sócio histórico. São Paulo: Scipione, 1993.

PARREIRA, Pedro et al.. A Observação Participante enquanto metodologia de investigação qualitativa. CIAIQ 2017, v. 3, 2017. Disponível em: https://proceedings.ciaiq.org/index.php /ciaiq2017/article/view/1447/1404. Acesso em: 10 ago. 2018.

REIS, Lucia. Por um mundo mais bacana. Rio de Janeiro: FTD, 2013.

RIBEIRO, Amélia Escotto do Amaral. Temas atuais em pedagogia empresarial: aprender para ser competitivo. 3. ed. Rio de Janeiro: Wak, 2010.

ROGERS, Elizabeth; KOSTIGEN, M. Thomas. O livro verde. Tradução de Bernardo Araújo. Rio de Janeiro: Sextante, 2009.

TRIVIÑOS, Augusto Nibaldo Silva. Introdução à pesquisa em ciências sociais: a pesquisa qualitativa em educação. São Paulo: Atlas, 1987.

VALLAEYS, François. Que significa responsabilidade social universitária. Revista Estudos, v. 36, p. 35-55, 2006.

WOLF, Rosângela Abreu do Prado. Pedagogia hospitalar: a prática do pedagogo em instituição não-escolar. Revista Conexão UEPG, v. 3, n. 1, 2007. Disponível em: http://revistas2.uepg.br/index.php/conexao/ article/viewFile/3836/2714. Acesso em: 07 ago. 2018.

Persp. Online: hum \& sociais aplicada., Campos dos Goytacazes, 26 (9) 62-81- 2019 seer.perspectivasonline.com.br 